\title{
THE EFFECTIVENESS OF PHARMACIST-LED MEDICATION REVIEW IN PETALING DISTRICT HEALTH OFFICE
}

\author{
WAN MAISARAH WAN AHMAD KAMAL ${ }^{1 *}$, LEE MEE CHAN ${ }^{2}$, ZAKIAH ABAS $^{3}$, \\ DARISHINI MURUGIAH ${ }^{1}$, GOH YEN JOE ${ }^{4}$, NADHRAH RASYIDAH RAMLI5, LUI \\ PARK YEANG ${ }^{4}$, ABDULLAH AZIM ZULKAFLI $^{2}$ AND WONG KENG WEI ${ }^{6}$ \\ ${ }^{1}$ Taman Medan Health Clinic, Petaling District Health Office, Selangor, Malaysia \\ ${ }^{2}$ Seksyen 7 Shah Alam Health Clinic, Petaling District Health Office, Selangor, Malaysia \\ ${ }^{3}$ Kelana Jaya Health Clinic, Petaling District Health Office, Selangor, Malaysia \\ ${ }^{4}$ Puchong Health Clinic, Petaling District Health Office, Selangor, Malaysia \\ ${ }^{5}$ Seksyen 19 Health Clinic, Petaling District Health Office, Selangor, Malaysia \\ ${ }^{6}$ Seri Kembangan Health Clinic, Petaling District Health Office, Selangor, Malaysia
}

Published online: 23 November 2021

To cite this article: WAN MAISARAH WAN AHMAD KAMAL, LEE MEE CHAN, ZAKIAH ABAS, DARISHINI MURUGIAH, GOH YEN JOE, NADHRAH RASYIDAH RAMLI, LUI PARK YEANG, ABDULLAH AZIM ZULKAFLI \& WONG KENG WEI (2021) The effectiveness of pharmacist-led medication review in Petaling District Health Office, Malaysian Journal of Pharmaceutical Sciences, 19(2): 97-110. https://doi.org/10.21315/mjps2021.19.2.7

To link to this article: https://doi.org/10.21315/mjps2021.19.2.7

\begin{abstract}
Medication review is an important service in optimising medicine use and improves clinical outcomes. This study aims to assess the effectiveness of pharmacist-led medication review on patients' knowledge and adherence. For this prospective study, 480 patients were randomly recruited in six primary healthcare clinics in Petaling District Health Office. Patients were interviewed with a questionnaire and validated medication adherence scale during recruitment and at follow-up visit to assess their medication knowledge and adherence. The data was analysed using Chi-square tests and paired t-tests to determine the correlation between medication knowledge and adherence with patient demographics. Among 408 patients that had completed the follow-up, $16.9 \%$ of patients showed medication knowledge deficits on recruitment. However, there is a significant improvement in the medication knowledge indices during the follow-up session $(p<0.001)$. Elderly patients were found to benefit from medication review with better medication knowledge and adherence postmedication review. The study found that the number of good adherers increased by $29.3 \%$ after the medication review. A further study demonstrating the effectiveness of medication review in cultivating knowledge retention and sustained adherence in the longer-term is warranted. Future work shall also focus on measuring the cost-effectiveness of pharmacistled medication review implementation in primary healthcare settings. Pharmacist-led medication review is an essential and effective service in primary health care facilities for patients to enhance their knowledge on their medications, and adherence especially in elderly patients on chronic medications.
\end{abstract}

"Corresponding author: wansarahkamal@gmail.com

(c) Penerbit Universiti Sains Malaysia, 2021. This work is licensed under the terms of the Creative Commons Attribution (CC BY) (http://creativecommons.org/licenses/by/4.0/). 
Keywords: Pharmacist, Medication review, Patient medication knowledge, Medication adherence, Primary care

\section{INTRODUCTION}

To date, the deepening burden of managing diseases amongst patients presents enormous challenges to the public primary care workforce. Patients are usually prescribed several medications to manage their multiple comorbidities and achieve therapeutic outcomes. However, there are risks of drug-related issues associated with the increased number of medications prescribed (Freyer et al. 2018; Ramli, Ahmad and Paraidathathu 2012). This subsequently led to suboptimal management, poor clinical outcomes, increased health costs, increased hospital stays and an increased economic burden on the country's healthcare system (Freyer et al. 2018; Ramli, Ahmad and Paraidathathu 2012). Examples of drug-related problems include polypharmacy, drug-drug interactions, non-adherence and undesired side effects among others (Kaufmann et al. 2015). A study by Costa et al. (2015) showed that the primary contributing factor to unsatisfactory clinical outcomes was patients' poor medication knowledge and adherence. Additionally, insufficient knowledge and education regarding proper medication administration contributed to drug-related problem occurrence (Hammerlein, Griese and Schulz 2007). Mainly, knowledge on medication was a significant parameter in determining patients' medication adherence whereby patients with sufficient medication knowledge were able to show good propensity to therapy adherence (Jankowska-Polańska et al. 2016; Awwad et al. 2015; Karaeren et al. 2009; Salama, Yasin and Elbarbary 2017).

Medication review can be a platform to educate patients on medication knowledge, which potentially can lead to an improvement in adherence. Medication review is defined as structured, critical interpretation of patients' prescribed drugs with aims to optimise drug use, enhance therapeutic outcome while identifying and resolving medicationrelated issues, and reducing waste (Pharmaceutical Care Network Europe n.d.; Clyne, Blekinsopp and Seal 2008). Comorbidities present in patients often require continuous multiple pharmacotherapies which subsequently increase the risk of drug-related problems (Freyer et al. 2018). The Royal Pharmaceutical Society encouraged the need for medication review for prescriptions with more than four medications as this was able to produce positive outcomes in medication usage. Medication review helped by facilitating capture and mitigation of pharmaceutical care issues, and hence, simultaneously decreasing the number of hospital admissions (Royal Pharmaceutical Society 2013; Jankowska-Polańska et al. 2016; Krska et al. 2001; Graaback \& Kjeldsen 2013; Christensen \& Lundh 2016).

In the current practice in Malaysia, medication reviews are often performed by prescribers and pharmacists to patients or caregivers. However, there is a lack of study findings on the effectiveness of medication reviews conducted by healthcare providers particularly pharmacists in Malaysia. Accordingly, the objective of this study was to fill the research gap in determining the effectiveness of medication reviews performed by pharmacists, and the correlation between patient's demographics and medication knowledge and adherence.

Malay J Pharm Sci, Vol. 19, No. 2 (2021): 97-110 


\section{METHODS}

\section{Study Design}

This exploratory study was conducted in the primary healthcare facilities in the central region of Malaysia under the jurisdiction of Petaling District Health Office from March to June 2020. Approval to conduct the study was obtained from the Malaysian Medical Research and Ethics Committee (MREC) with patient informed consent obtained prior to study participation.

\section{Study Sample}

The study was conducted in six primary healthcare clinics with various patient demographics. Patients with chronic diseases who had regular appointments encountered at the pharmacy screening counter were invited to participate in the study. Purposive sampling method was used to recruit potential participants, whereby every tenth chronic illness patient that arrived at the pharmacy screening counter was invited to participate in the study. Participants had to meet the following eligibility criteria: a) they were at least 18 years old; b) diagnosed with type 2 diabetes mellitus (T2DM) and/or hypertension, and lastly, c) they were prescribed a minimum of four medications. To calculate the sample size suitable for the study, the total number of repeat prescriptions from the six primary health clinics was used, with a margin error of $5 \%$ and a confidence level of $95 \%$. Using the sample size calculation for large population stated below (Cochran 1963), a minimum sample size of $n=384$ was required for the study.

$$
\text { Sample size, } \begin{aligned}
n & =Z^{2} \times(p) \times\left[(1-p) / C^{2}\right] \\
& =(1.96)^{2} \times[(0.5) \times(1-0.5)] /(0.05)^{2} \\
& =384.16 \approx 384 \text { participants }
\end{aligned}
$$

\section{Study Instrument}

The data collection process was conducted by trained on-site pharmacists in their respective healthcare facilities. There were two parts of the data collection process involved in the study; one was questionnaire administration, and followed by medication review. The study questionnaire was administered twice; once during study recruitment and another during a follow-up visit (one-month post-medication review). Following the initial questionnaire administration, a structured medication evaluation or medication review was conducted in a counselling room. The first section of the questionnaire consisted of four parts, namely: a) demography, b) patient knowledge, c) other information related to participant's medication knowledge, and d) medication adherence scale. The second section of the questionnaire was the medication knowledge index scoring system adapted from a study by Goh et al. (2014) to identify the five indices of medication knowledge.

$$
\begin{gathered}
\text { Medication knowledge index scoring system }=\frac{\begin{array}{l}
\text { Number of medications correctly } \\
\text { verbalised for each knowledge index }
\end{array}}{\text { Total number of medications }} \\
\text { patients is prescribed }
\end{gathered}
$$


The responses for the items were scored 1 when the participant answered correctly, and scored 0 when the participant answered wrongly. For example, three medications with indications correctly verbalised/a total of six medications $=0.5$. Total score $=\Sigma$ (patient's individual medication knowledge index score). A total score of 1 indicated participants has verbalised all answers correctly.

The questionnaire was originally in English and then translated into Bahasa Malaysia. Face and content validation was performed by a panel consisting of a research and development committee, and senior pharmacists. Modifications were made based on the feedback gathered to improve the questionnaire clarity, consistency and presentation. A pilot study was conducted among 39 respondents, followed by a reliability test. Cronbach's alpha obtained for the first section of the questionnaire was 0.82 . Meanwhile, the medication adherence scale used was adapted from a study by Ramli, Ahmad and Paraidathathu (2012) with a four-point Likert-type response format (none of the time $=4$, some of the time $=3$, most of the time $=2$, and all the time $=1$ ). The Cronbach's alpha calculated for this scale was to be 0.78 .

Medication adherence was measured and categorised as follows:

a) Adherence $=$ a full score of 28 or a score of 27 (due to 1 point deducted from any one of the 'unintentional adherence' questions, which were question 1 or question 6)

b) Non-adherence $=$ a score of 26 and below

\section{Statistical Methods}

Statistical software for analysis used in the study was SPSS 26.0. A multivariate analysis of Pearson and McNemar test was conducted to determine the significant correlation of demographics on participants' medication knowledge and adherence scores. A paired $t$-test was also used to determine the significant correlation of demographics on participants' medication knowledge and adherence scores.

\section{RESULT}

\section{Sample Characteristics}

A total of 480 participants were recruited for this study, of whom 408 completed the followup $(85 \%)$, and a $15 \%$ dropout rate. Nearly half of the participants were aged 61 years old and above $(n=190 / 408,46.6 \%)$. More than three-quarters of the participants were married $(n=320 / 408,78.4 \%)$, and live with family members $(n=388 / 408,95.1 \%)$. Ninety percent of the participants were able to take their medications independently $(n=371 / 408)$, with the remaining of them requiring a caregiver and/or assistance to ease the administration of medications ( $n=37 / 408,9.1 \%)$. There were $60 \%$ of participants prescribed a minimum of four medications $(n=241 / 408)$ with the remaining $40 \%(n=167 / 408)$ requiring a more complex treatment regimen (more than five medications). Patient demographic and characteristics data are shown in Table 1.

Malay J Pharm Sci, Vol. 19, No. 2 (2021): 97-110 
Table 1: Patient demographic and characteristics.

\begin{tabular}{|c|c|}
\hline Total number of subjects recruited & $\begin{array}{l}n=408 \\
n(\%)\end{array}$ \\
\hline \multicolumn{2}{|l|}{ Gender } \\
\hline Female & $220(53.9)$ \\
\hline Male & $188(46.1)$ \\
\hline \multicolumn{2}{|l|}{ Age (years old) } \\
\hline $31-45$ & 49 (12.0) \\
\hline $45-60$ & $169(41.4)$ \\
\hline$\geq 61$ & $190(46.6)$ \\
\hline mean \pm SD & $58.2 \pm 10.3$ \\
\hline \multicolumn{2}{|l|}{ Ethnicity } \\
\hline Chinese & $101(24.8)$ \\
\hline Indian & $98(24.0)$ \\
\hline Malay & $205(50.2)$ \\
\hline Others & $4(1.0)$ \\
\hline \multicolumn{2}{|l|}{ Education level } \\
\hline No education & $21(5.1)$ \\
\hline Primary & $94(23.0)$ \\
\hline Secondary & $225(55.1)$ \\
\hline Tertiary & $68(16.7)$ \\
\hline \multicolumn{2}{|l|}{ Working status } \\
\hline Not working & $260(63.7)$ \\
\hline Working & $148(36.3)$ \\
\hline \multicolumn{2}{|l|}{ Living status } \\
\hline Alone & $18(4.4)$ \\
\hline Family & $388(95.1)$ \\
\hline Friends & $2(0.5)$ \\
\hline \multicolumn{2}{|l|}{ Marital status } \\
\hline Married & $320(78.4)$ \\
\hline Single & $29(7.1)$ \\
\hline Widowed & $54(13.2$ \\
\hline Divorced & $5(1.2)$ \\
\hline \multicolumn{2}{|l|}{ Administration of medications } \\
\hline Self & $371(90.9)$ \\
\hline Caregiver & $37(9.1)$ \\
\hline
\end{tabular}

(continued on next page) 
Table 1: (continued)

\begin{tabular}{ll}
\hline Total number of subjects recruited & $\begin{array}{l}\boldsymbol{n}=\mathbf{4 0 8} \\
\boldsymbol{n}(\%)\end{array}$ \\
\hline Mean number of medications prescribed \pm SD & $5.4 \pm 2.0$ \\
Medication aids & $309(75.7)$ \\
$\quad$ None & $99(24.3)$ \\
\hline Pillbox &
\end{tabular}

Note: $\mathrm{SD}=$ standard deviation

\section{MEDICATION KNOWLEDGE}

Amongst the 408 participants recruited in the study, 24.8\% ( $n=101 / 408)$ had issues with medication indication; $15.2 \%(n=62 / 408)$ had issues with medication dose; $8.6 \%$ ( $n=35 / 408)$ had issues with the frequency of medication; $2.0 \%(n=8 / 408)$ did not know the proper storage conditions of their medication; and $15.4 \%(n=62 / 408)$ had issues with medication administration. Subsequently, at the follow-up visit, the percentage of participants who were able to verbalise the correct indication, dose, frequency, storage condition and administration of their medications improved by $21.1 \%, 12.3 \%, 4.2 \%, 9.0 \%$ and $2.0 \%$, respectively, after medication review (Figure 1 ).

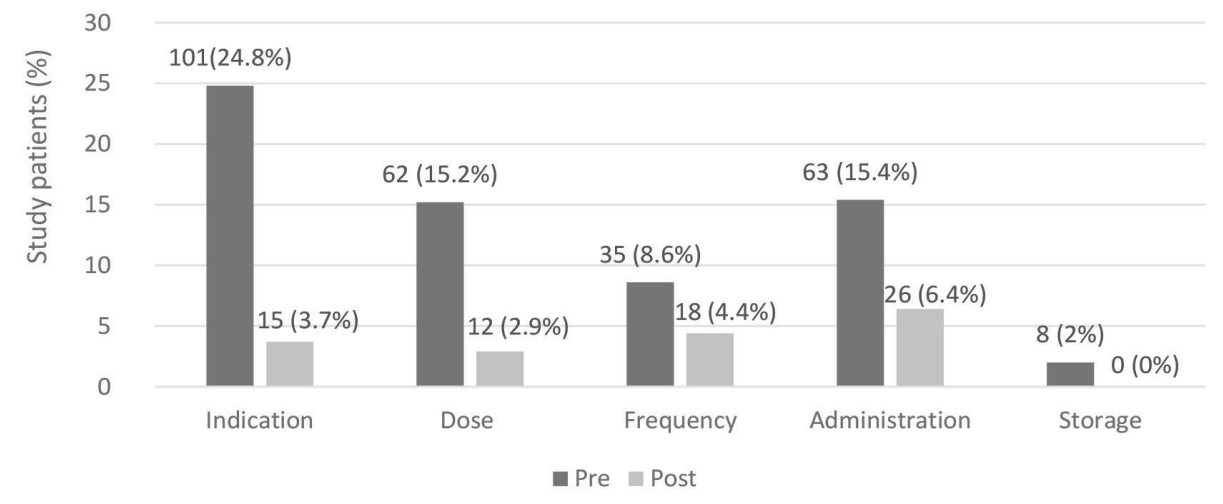

Figure 1: Knowledge deficiency in medication knowledge five indices in $n=408$ participants.

At baseline, elderly participants ( $\geq 61$ years old) were found to have a lower medication knowledge $(n=163 / 408,40 \%)$ compared to non-elderly participants $(n=$ $189 / 408,44.1 \%$ ). Following the follow-up visit, elderly participants ( $\geq 61$ years old) had shown improvement in medication knowledge after the medication review with a $4.6 \%$ increment (Table 2). Meanwhile, younger participants showed an improvement in medication knowledge of $7.4 \%$ after the medication review. In this study, it was found that the younger participants $(<61$ years old) were generally better educated $(p<0.001)$. It was also shown in Table 2 that participants with at least secondary education levels had higher improvement (9.5\% increment) in medication knowledge compared to lower education levels.

Malay J Pharm Sci, Vol. 19, No. 2 (2021): 97-110 
Table 2: Number of participants with total medication knowledge score of 1 (correctly verbalised all answers in five knowledge indices) pre- and post-medication review in different age group and education status.

\begin{tabular}{lll}
\hline Demographic & \multicolumn{2}{l}{$\begin{array}{l}\text { Number of participants with medication } \\
\text { knowledge score of } \mathbf{1}, \boldsymbol{n}(\%)\end{array}$} \\
\hline & Pre- & \multicolumn{1}{c}{ Post- } \\
\hline Age group & & \\
$\quad<61$ years old & $180(44.1)$ & $210(51.5)$ \\
$\geq 61$ years old & $163(40.0)$ & $182(44.6)$ \\
Education status & & \\
No education & $16(3.9)$ & $20(4.9)$ \\
Primary & $82(19.9)$ & $92(22.5)$ \\
Secondary & $188(46.1)$ & $215(52.7)$ \\
Tertiary & $53(13.0)$ & $65(15.9)$ \\
\hline
\end{tabular}

\section{Medication Adherence}

Table 3 in this study showed that at baseline, $43 \%$ of participants were adherent to their medications. After medication review, an improvement of adherence by $43.2 \%$ to $72.5 \%$ was noted (29.3\% increment). Meanwhile, a decrease of $23.3 \%$ was also noted from the non-adherent group post-medication review. Furthermore, from Table 4 provided, it was shown that three-fifths of participants $(n=249 / 408,61 \%)$ claimed to have never forgotten to consume their medicine in the past one-month post-medication review, which is an improvement of $20 \%$ from pre-medication review scores. Additionally, Table 4 also showed overall mean scores improvement from pre- and post-medication review (higher mean score than baseline) especially on both unintentional (Question 1 and 6) and intentional missed/skipped dose (Question 2, 3, 4, 5 and 7).

Table 3: Medication adherence distribution at pre- and post-medication review.

\begin{tabular}{llll}
\hline Adherence score & Adherence status & Pre- $\boldsymbol{n}(\%)$ & Post- $\boldsymbol{n}(\%)$ \\
\hline 28 & Adherer & $86(21.1)$ & $196(48.0)$ \\
$\begin{array}{l}27 \text { (one point deducted from either question } \\
1 \text { or 6) }\end{array}$ & Adherer & $90(22.1)$ & $100(24.5)$ \\
$\begin{array}{l}27 \text { (one point deducted due to other } \\
\text { question) }\end{array}$ & Non-adherers & $31(7.6)$ & $28(6.9)$ \\
$23-26$ & Non-adherers & $179(43.9)$ & $80(19.6)$ \\
$7-22$ & Non-adherers & $22(5.4)$ & $4(0.1)$ \\
\hline
\end{tabular}

Notes: Adherers were those that scored a full score of 28 or a score of 27 (due to only one point deducted from Question 1 or Question 6), as described in the method section. 
Table 4: Adherence scores pre and post-medication review.

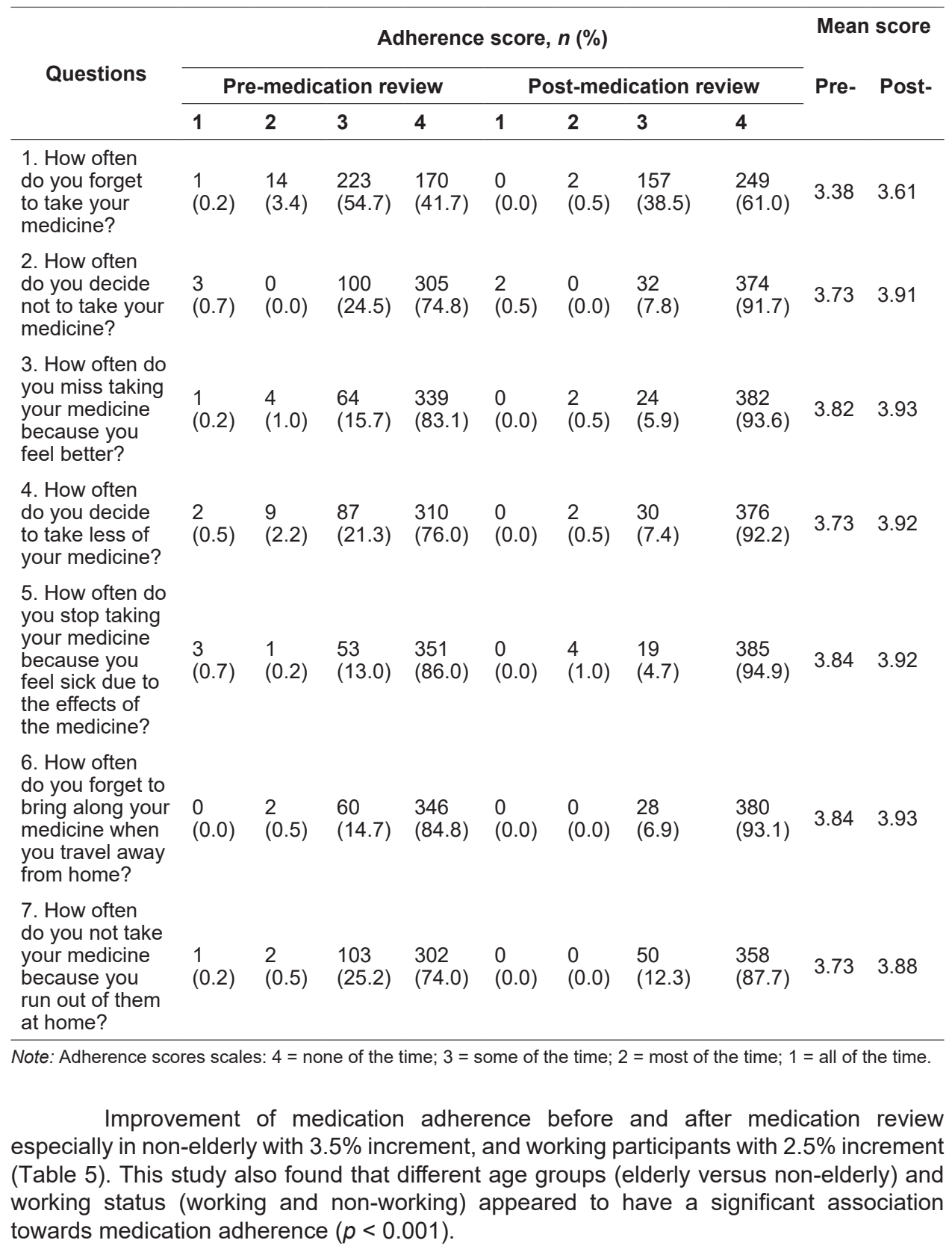

Malay J Pharm Sci, Vol. 19, No. 2 (2021): 97-110 
Table 5: Improvement in participants' adherence pre- and post-medication review.

\begin{tabular}{lccc}
\hline Demographic & \multicolumn{2}{c}{ Number of adherent participant, $\boldsymbol{n}(\%)$} & p-value \\
\cline { 2 - 3 } & Pre- & \multicolumn{1}{c}{ Post- } & \\
\hline Age & & & \\
$<61$ years old & $220(53.9)$ & $234(57.4)$ & $<0.001^{\text {a }}$ \\
$\geq 61$ years old & $166(40.7)$ & $170(41.7)$ & \\
& & & \\
Working status & & & \\
Not working & $250(61.3)$ & $258(63.2)$ & $<0.001^{\text {b }}$ \\
Working & $136(33.3)$ & $146(35.8)$ & \\
\hline
\end{tabular}

Notes: a ${ }^{p}$-value based on McNemar test with binomial distribution used. Two cells (50\%) have expected count less than 5 . The minimum expected count is 1.69 ; ${ }^{b} p$-value based on McNemar test with binomial distribution used. Two cells $(50 \%)$ have expected count less than 5 . The minimum expected count is 1.45 .

\section{Correlation Between Medication Knowledge and Adherence}

A paired $t$-test was run to predict the association between participants' medication knowledge and adherence. Based on Table 6, there is a significant association between medication knowledge and adherence $(p<0.001)$.

Table 6: Correlation between participants' medication knowledge and adherence.

\begin{tabular}{llllll}
\hline Mean (SD) & SD & $\begin{array}{l}\text { Standard error } \\
\text { mean }\end{array}$ & $\begin{array}{l}\text { 95\% Confidence } \\
\text { interval difference }\end{array}$ & -stats (df) & $p$-value \\
\hline 2.8533 & 0.3224 & 0.160 & $2.8220,2.8847$ & $178.77(407)$ & 0.000 \\
\hline
\end{tabular}

\section{DISCUSSION}

From the analysis, it was found that most elderly patients ( $\geq 61$ years old) have an issue with medication knowledge and adherence. Elderly patients in the study are shown to have a low baseline level of knowledge and adherence during pre-medication review and significant improvement $(p<0.001)$ can be seen after the medication review (Table 5). Other studies also show that elderly patients are the ones who benefited most from medication review (Lowe et al. 2000; Conn et al. 2009; Goh et al. 2014; Awwad et al. 2015). Therefore, elderly patients should be enrolled for medication review regardless of the number of medications they are taking, as well as elderly patients with other probable contributing factors affecting adherence (Tsai et al. 2012; Smaje et al. 2018). The cognitive and memory function diminishes as age increases; thus, elderly patients have trouble processing information given during dispensing at the counter. This can be further worsened when they are also having difficulty in reading the medication label due to vision impairment. Furthermore, a lack of understanding of medication labels despite the written information regarding the indication, dosage and frequency on the labels might require the presence of a caregiver for some patients (Insel et al. 2006; Shruthi et al. 2016). A medication review can help patients to see the overall picture of their medication regimen, and improve medication understanding by simplifying their medication regimen. This includes advise on medication 
administration by suggesting various methods to aid compliance such as preparation of pillbox, setting an alarm or sticky note as a reminder, and getting help from family members and friends to remind them to avoid missing medication dose.

Intentional non-adherence can be due to the lack of knowledge and understanding of their medication importance (Awwad et al. 2015). Some patients, including younger patients, would only consume their medications when they deemed necessary, usually after they have felt the symptoms, or only after allaying the aversion to continue taking their medication (Awwad et al. 2015; Kvarnström, Airaksinen and Liira 2018). Another intentional non-adherence can be contributed to by false beliefs and myths regarding the medication regimen (Molloy et al. 2014). Patients' beliefs and attitudes demonstrate their intentions to follow their medication regimen. Intending or readiness to adhere is essential to following treatment advise (Willey et al. 2000). Therefore, revising patients' beliefs according to evidence-based facts during medication counselling and review could help to achieve therapeutic goals and avoid further comorbidities.

The power of the sample size obtained was sufficient to demonstrate that patients with higher education levels have higher medication knowledge levels and achieved more improvement compared to lower education levels $(p<0.001)$. This can be found in other studies as well that investigate education level factors in patient's medication knowledge (Ponnusankar et al. 2004; Alkatheri and Albekairy 2013; Awwad et al. 2015; Najjar et al. 2015; Shruthi et al. 2016; Gast and Mathes 2019; Mekonnen and Gelayee 2020). This can be attributable to the higher awareness among them, resulting in their effort to understand their medication regimen and develop a better understanding regarding their medication, instruction, and advice. Those patients with lower-level education that may have difficulty in understanding instruction will benefit from a medication review. Moreover, it is also found in the study that some of the working patients showed a lower adherence rate compared to nonworking patients (Table 5). This may be due to patients' inability to incorporate medication administration into their working schedule and lifestyle, and not motivated in complying to their medication regime. These patients can benefit from medication review by detecting the issues that hinder them from adhering to their medication, tailoring interventions to the unique characteristics and lifestyle of patients, and help by discussing solutions for them.

From the 'other information related to participant's medication knowledge' part of the questionnaire conducted in this study, it was found that discussion with doctors may contribute to improving patients' medication knowledge although it is not significant ( $p=$ 0.387). This lack of significance may be because a medication review session performed by the pharmacist allows sufficient time to conduct proper medication counselling. It can also be due to the presence of physical medication that helps patients better visualise and understand their medication while doctors help by improving understanding of the disease process to patients. This was shown in few studies where doctors that solely conducted the medication review realised the need for pharmacist involvement in detecting all issues pertaining to patients' medication regimen (Kvarnström, Airaksinen and Liira 2018; Duncan et al. 2019). This further indicates the need for effective collaboration between doctors and pharmacists to achieve the full benefit of medication review. An improvement in collaboration between prescribers and pharmacists may offer greater benefits in the future particularly for the implementation of medication review through a joined-up service. This further indicates the need for effective collaboration between doctors and pharmacists has a positive impact on patient outcomes and achieves the full benefit of medication review.

Malay J Pharm Sci, Vol. 19, No. 2 (2021): 97-110 


\section{LIMITATION AND FUTURE RESEARCH}

One of the limitations of this study is the short duration of follow-up (one month). While this preliminary study on pharmacist-led medication review in primary health care facilities can be the baseline for future studies, a further study demonstrating the effectiveness of medication review in cultivating knowledge retention and sustained adherence in the longerterm is warranted. The second limitation is that the Malaysian Pharmaceutical Division of the Ministry of Health Malaysia has recently endorsed the Malaysian medication adherence assessment tool (MyMAAT) as the latest validated tool to measure medication adherence. Future research may benefit from the updated medication adherence assessment tool to obtain precise results. Future work shall also focus on measuring the cost-effectiveness of pharmacist-led medication review implementation in primary healthcare settings.

\section{CONCLUSION}

A $29.3 \%$ improvement in adherence rate among 408 patients one month after medication reviews were conducted showed that medication reviews conducted by pharmacists were able to improve patients' medication knowledge and adherence. A pharmacist-led medication review is essential and can be an effective service in the primary health care facilities for patients to enhance their knowledge on their medications, and adherence especially in elderly patients on chronic medications.

\section{ACKNOWLEDGEMENTS}

The authors would like to thank Khairani Azian Khairudin and Research and Development Committee of Petaling District Health Office for the useful discussions and suggestions.

\section{REFERENCES}

ALKATHERI, A. \& ALBEKAIRY, A. (2013) Does the patients' educational level and previous counseling affect their medication knowledge? Annals of Thoracic Medicine, 8(2): 105. https://doi.org/10.4103/1817-1737.109823

AWWAD, O., AKOUR, A., AL-MUHAISSEN, S. \& MORISKY, D. (2015) The influence of patients' knowledge on adherence to their chronic medications: A cross-sectional study in Jordan, International Journal of Clinical Pharmacy, 37(3): 504-510. https://doi.org/10.1007/ s11096-015-0086-3

CHRISTENSEN, M. \& LUNDH, A. (2016) Medication review in hospitalised patients to reduce morbidity and mortality, The Cochrane Database of Systematic Review, 20(2): 1-68. https://doi.org/10.1002/14651858.CD008986.pub3

CLYNE, W., BLEKINSOPP, A. \& SEAL, R. (2008) A guide to medication review 2008. https://www.webarchive.org.uk/wayback/archive/20140627111246/http\%3A/www.npc.n hs.uk/review_medicines/intro/resources/room_for_review.pdf 
COCHRAN, W. (1963) Sampling techniques, $2^{\text {nd }}$ edition. (New York: John Wiley and Sons, Inc.).

COSTA, E., GIARDINI, A., SAVIN, M., MENDITTO, E., LEHANE, E., LAOSA, O. et al. (2015) Interventional tools to improve medication adherence: Review of literature, Patient Prefer Adherence,14(9): 1303-1314. https://doi.org/10.2147/PPA.S87551

CONN, V., HAFDAHL, A., COOPER, P., RUPPAR, T., MEHR, D. \& RUSSELL, C. (2009). Interventions to improve medication adherence among older adults: Meta-analysis of adherence outcomes among randomized controlled trials. The Gerontologist, 49(4): 447462. https://doi.org/10.1093/geront/gnp037

DUNCAN, P., CABRAL, C., MCCAHON, D., GUTHRIE, B. \& RIDD, M. (2019) Efficiency versus thoroughness in medication review: A qualitative interview study in UK primary care, British Journal of General Practice, 69(680): 190-198. https://doi.org/10.3399/ bjgp19X701321

FREYER, J., HUETER, L., KASPRICK, L., FRESE, T., SULTZER, R., SCHIEK, S. et al. (2018) A dual intervention in geriatric patients to prevent drug-related problems and improve discharge management, International Journal of Clinical Pharmacy, 40: 1189-1198. https://doi.org./10.1007/s11096-018-0643-7

GAST, A. \& MATHES, T. (2019) Medication adherence influencing factors - An overview of systematic reviews, Systematic Review, 8(112): 1-17. https://doi.org/10.1186/s13643019-1014-8

GOH, B. Q., TAY, A. H., KHOO, R. S., GOH, B. K., LO, P. F. \& LIM, C. J. (2014) Effectiveness of medication review in improving medication knowledge and adherence in primary care patients, Proceedings of Singapore, 23(2): 134-141. https://doi.org/10.1177/201010581402300207

GRAABACK, T. \& KJELDSEN, L. (2013) Medication reviews by clinical pharmacists at hospitals lead to improved patient outcomes: A systematic review. Basic \& Clinical Pharmacology \& Toxicology, 112: 359-373. https://doi.org/10.1111/bcpt.12062

HAMMERLEIN, A., GRIESE, N. \& SCHULZ, M. (2007) Survey of drug-related problems identified by community pharmacies, Annals of Pharmacotherapy, 41(11): 1825-1832. https://doi.org/10.1345/aph.1k207

INSEL, K., MORROW, D., BREWER, B. \& FIGUEREDO, A. (2006) Executive function, working memory, and medication adherence among older adults, Journal of Gerontology: Psychological Sciences, 61(2): 102-107. https://doi.org/10.1093/geronb/61.2

JANKOWSKA-POLANSKA, B., UCHMANOWICZ, I., DUDEK, K. \& MAZUR, G. (2016) Relationship between patients' knowledge and medication adherence among patients with hypertension, Patient Prefer Adherence, 10: 2437-2447. https://doi.org/10.2147/PPA. S117269

Malay J Pharm Sci, Vol. 19, No. 2 (2021): 97-110 
KARAEREN, H., YOKUSOGLU, M., UZUN, S., BAYSAN, O., KOZ, C. \& KARA, B. (2009) The effect of the content of the knowledge on adherence to medication in hypertensive patients, The Anatolian Journal of Cardiology, 9(3): 183-188.

KAUFMANN, C., STAMPFLI, D., HERSBERGER, K. \& LAMPERT, M. (2015) Determination of risk factors for drug-related problems: A multidisciplinary triangulation process, British Medical Journal Open, 5(3): e006376. https://doi.org/10.1136/bmjopen-2014-006376

KRSKA, J., CROMARTY, J., ARRIS, F., JAMIESON, D., HANSFORD, D. \& DUFFUS, P. (2001) Pharmacist-led medication review in patients over 65: A randomized, controlled trial in primary care, Age and Ageing, 30(3): 205-211. https://doi.org/10.1093/ageing/30.3.205

KVARNSTROM, K., AIRAKSINEN, M. \& LIIRA, H. (2018) Barriers and facilitators to medication adherence: A qualitative study with general practitioners, British Medical Journal, 8(1): 1-8. https://doi.org/10.1136/bmjopen-2016-015332

LOWE, C., RAYNOR, D., PURVIS, J., FARRIN, A. \& GUDSON, J. (2000) Effects of a medicine review and education programme for older people in general practice, British Journal of Clinical Pharmacology, 50(2): 172-175. https://doi.org/10.1046/j.1365-2125.2000.00247.x

MEKONNEN, G. \& GELAYEE, D. (2020) Low medication knowledge and adherence to oral chronic medications among patients attending community pharmacies: A crosssectional study in a low-income country, BioMed Research International, 2020: 1-8. https://doi.org/10.1155/2020/4392058

MOLLOY, G., MESSERLI-BURGY, N., HUTTON, G., WILKMAN, A., PERKINS-PORRAS, L. \& STEPTOE, A. (2014) Intentional and unintentional non-adherence to medications following an acute coronary syndrome: A longitudinal study, Journal of Psychosomatic Research, 76(5): 430-432. https://doi.org/10.1016/j.jpsychores.2014.02.007

NAJJAR, A., AMRO, Y., KITANEH, I., ABU-SHARAR, S., SAWALHA, M., JANOUS, A. et al. (2015) Knowledge and adherence to medications among Palestinian geriatrics living with chronic diseases in the West Bank and East Jerusalem, PLOS ONE, 10(6): 1-10. https://doi.org/10.1371/journal.pone.0129240

PHARMACEUTICAL CARE NETWORK EUROPE (n.d.). https://www.pcne.org/workinggroups/1/medication-review (13 February 2020).

PONNUSANKAR, S., SURULIVELRAJAN, M., ANANDAMOORTHY, N. \& SURESH, B. (2004) Assessment of impact of medication counseling on patients' medication knowledge and compliance in an outpatient clinic in South India, Patient Education and Counseling, 54(1): 55-60. https://doi.org/10.1016/S0738-3991(03)00193-9

RAMLI, A., AHMAD, N. S. \& PARAIDATHATHU, T. (2012) Medication adherence among hypertensive patients of primary health clinics in Malaysia, Patient Prefer Adherence, 6: 613-622. https://doi.org/10.2147/PPA.S34704

ROYAL PHARMACEUTICAL SOCIETY (2013) Improving patient outcomes: The better use of multi-compartment aids (13 February 2020). 
SALAMA, A., YASIN, A. \& ELBARBARY, W. (2017) Medication knowledge as a determinant of medication adherence in geriatric patients, Serse Elian City, Menoufia Governorate, Egypt, Menoufia Medical Journal, 30(1): 63-68. https://doi.org/10.4103/1110- 2098.211476

SHRUTHI, R., JYOTHI, R., PUNDARIKAKSHA, H., NAGESH, G. \& TUSHAR, T. (2016) A study of medication compliance in geriatric patients with chronic illnesses at a tertiary care hospital, Journal of Clinical and Diagnostic Research, 10(12): 40-43. https://doi.org/10.7860/JCDR/2016/21908.9088

SMAJE, A., WESTON-CLARK, M., RAJ, R., ORLU, M., DAVIS, D. \& RAWLE, M. (2018) Factors associated with medication adherence in older patients: A systematic review, Aging Medicine, 1(3): 254-266. https://doi.org/0.1002/agm2.12045

TSAI, K., CHEN, J., WEN, C., KUO, H., LU, I., CHIU, L. et al. (2012) Medication adherence among geriatric outpatients prescribed multiple medications, The American Journal of Geriatric Pharmacotherapy, 10(1): 61-68. https://doi.org/10.1016/j.amjopharm.2011.11.005

WILLEY, C., REDDING, C., STAFFORD, J., GARFIELD, F., GELETKO, S., FLANIGAN, T. et al. (2000) Stages of change for adherence with medication regimens for chronic disease: Development and validation of a measure, Clinical Therapy, 22(7): 858-871. https://doi.org/10.1016/s0149-2918(00)80058-2 